University of Nebraska - Lincoln

DigitalCommons@University of Nebraska - Lincoln

Drought Mitigation Center Faculty Publications Drought -- National Drought Mitigation Center

2004

\title{
An Agricultural Drought Risk-Assessment Model for Corn and Soybeans
}

\author{
Hong Wu \\ University of Nebraska-Lincoln \\ Kenneth G. Hubbard \\ University of Nebraska-Lincoln, khubbard1@unl.edu \\ Donald A. Wilhite \\ University of Nebraska-Lincoln, dwilhite2@unl.edu
}

Follow this and additional works at: https://digitalcommons.unl.edu/droughtfacpub

Part of the Climate Commons, Environmental Indicators and Impact Assessment Commons, Environmental Monitoring Commons, Hydrology Commons, Other Earth Sciences Commons, and the Water Resource Management Commons

Wu, Hong; Hubbard, Kenneth G.; and Wilhite, Donald A., "An Agricultural Drought Risk-Assessment Model for Corn and Soybeans" (2004). Drought Mitigation Center Faculty Publications. 37.

https://digitalcommons.unl.edu/droughtfacpub/37

This Article is brought to you for free and open access by the Drought -- National Drought Mitigation Center at DigitalCommons@University of Nebraska - Lincoln. It has been accepted for inclusion in Drought Mitigation Center Faculty Publications by an authorized administrator of DigitalCommons@University of Nebraska - Lincoln. 
Published in International Journal of Climatology 24 (2004), pp. 723-741; doi: 10.1002/joc.1028. Copyright (c) 2004 Royal Meteorological Society. Published by Wiley InterScience. Used by permission.

Submitted September 5, 2003; revised January 5, 2004; accepted January 17, 2004.

\title{
An Agricultural Drought Risk-Assessment Model for Corn and Soybeans
}

\author{
Hong $\mathrm{Wu},{ }^{1,2}$ Kenneth G. Hubbard, ${ }^{2}$ and Donald A. Wilhite ${ }^{1}$
}

1. National Drought Mitigation Center, University of Nebraska, Lincoln, NE 68583-0728, USA

2. High Plains Regional Climate Center, University of Nebraska, Lincoln, NE 68583-0728, USA

Corresponding author - Hong Wu, National Drought Mitigation Center, University of Nebraska, Lincoln, NE 68583-0728, USA; email hwu2@unl.edu

\begin{abstract}
An agricultural drought risk-assessment model was developed for Nebraska, USA, for corn and soybeans on the basis of variables derived from the standardized precipitation index and crop-specific drought index using multivariate techniques. This model can be used to assess real-time agricultural drought risk for specific crops at critical times before and during the growing season by retaining previous, and adding current, weather information as the crops pass through the various development stages. This model will be helpful to decision makers, ranging from agricultural producers to policy makers and from local to national levels. The results of the model validation using three different datasets show that the risk-assessment accuracy improves as the crop develops. At the end of April, before corn is planted, the average assessment accuracy rate of drought risks on final yield is $60 \%$. At the beginning of July, when corn is at the vegetative stage, the average assessment accuracy rate reaches $76 \%$. In late July, when corn is at the ovule stage, the rate increases to $85 \%$. The rates are $89 \%$ in the second half of August and the end of September, when corn is at the reproduction and ripening stages respectively. The model assessment accuracy for soybeans is lower than that for corn at the same growth stages because weather has less impact on soybeans than on corn. A reliable assessment, with $80 \%$ assessment accuracy rate, begins at mid-August, when soybeans are at pod formation stage. In early September and October, when soybeans are at pod fill and ripening stages respectively, the model is able to assess risks on soybean yield with $83 \%$ and $81 \%$ accuracy rates respectively.
\end{abstract}


Keywords: Nebraska, principal component analysis, discriminant analysis, agricultural drought, risk assessment, yield loss, SPI, CSDI

\section{Introduction}

Nebraska has experienced numerous droughts with varying magnitude, duration, and extent since precipitation was first recorded in the state (Williams and Murfield, 1977). Agriculture is the primary economic sector affected by drought in Nebraska. Because of repeated and widespread severe drought impacts in Nebraska, more emphasis on drought risk management is warranted (Anon, 2002).

It is most critical to detect potential agricultural drought risk at preplanting and early crop-growth stages, when policy makers have sufficient time to implement strategies to reduce risk potential. This information could also be used by farmers to make decisions on whether to purchase crop insurance (Luo et al., 1994) or alter planting and cultivation strategies. Therefore, a reliable agricultural drought risk early-warning system and an assessment of risks for specific crops would offer opportunities for reducing the impact of drought on crops and provide significant benefit to crop producers, agribusinesses, and related commerce.

Numerous studies have used growing-season climatic data (i.e., precipitation, temperature, evapotranspiration) to estimate drought risk in specific regions (e.g., McDonald, 1989; Dietz et al., 1998; Keating and Meinke, 1998). These studies have provided valuable information for drought risk assessment. However, there are limitations among the approaches taken by these researchers. First, the risk assessment is not conducted in a timely manner and is not related to crop phenology. Most studies did not establish a realtime operational system to assess drought risk to crops. For instance, Dietz et al. (1998) developed an index to assess drought risk for dryland agriculture in the semiarid region of India. However, this index was used as a risk evaluation only on the historical years 195793. Although some researchers have studied drought risk as a function of time of year (e.g., Nullet and Giambelluca, 1988), the time periods often did not match the crop's phenological stages, making it difficult to develop strategies to minimize the risk of drought damage. Second, the time scale of the climatic data used in the assessment is usually based on monthly precipitation and temperature during the growing season (Dennett et al., 1980; Luo et al., 1994). The monthly time scale limits the opportunity to assess the impact of droughts and other climatic extremes that occurred for shorter intervals or to associate the water stress to critical growth stages that are less than a month in length (Hill et al., 1980). Third, some studies are primarily based on local field experiments and empirical assumptions that prohibit direct application to other regions and crops (e.g., Bailey and Boisvert, 1989). Additionally, data needed in the assessment are not available or reliable in many regions. For example, the dataset required for the study of Chipanshi et al. (1997) included weather data (temperature, solar radiation, and precipitation), soil data (physical and chemical), crop data (genetic response to weather), and management data (agronomic practice). Fourth, most of the studies use weather data to establish a precise numerical relationship with crop yield and then assess drought impacts (e.g., Walker, 1989; Kumar and Panu, 1997; Keating and Meinke, 1998). Crop yield, however, is influenced by many 
factors other than weather. In addition, the weather data used may not accurately represent the actual climate conditions in those areas where the majority of yield is obtained (Easterling et al., 1988). Therefore, in practice, a precise numerical relationship between yield and only weather data is difficult to establish.

The purpose of this study is to develop a methodology to assess agricultural drought risk for Nebraska, USA, as related to crop yield. This methodology has the following characteristics. First, the risk assessment will be crop-specific for corn and soybeans, because these two are major crops that exhibit different sensitivities to water stress (Wilhite, 1982). Second, this study will integrate a few well-developed drought indices as moisture supply indicators. There is a tendency to evaluate drought severity using several indices or variables. For instance, the scientists within the National Drought Mitigation Center (NDMC), Climatic Prediction Center (CPC, NOAA) and US Department of Agriculture (USDA) have developed an integrated product, the Drought Monitor, which is a synthesis of several different scientific drought indices (Svoboda et al., 2002; NDMC/NOAA/USDA, 2003). Third, the risk will be assessed at critical crop times before and during the growing season, and the moisture indicators will be updated as the crop develops. Fourth, this study will not follow the traditional regression approach to set up a precise numerical relationship between moisture indicators and crop yield. Instead, this study will identify agricultural drought-risk areas through other multivariate techniques. Fifth, this study will present a framework to assess agricultural drought risk in the study area. For other regions beyond this study, a model validation will be necessary to apply the methodology. Finally, the risk assessment results will be presented by combining model outputs with crop distribution in a geographical information system (GIS).

\section{Methodology}

The data required to develop the model include: indicators of moisture supply, which are represented by selected existing drought indices; and an indictor of agricultural drought risk because of limited moisture supply, which is represented by rain-fed crop yield residuals. Preparation of data will be presented first and then the procedures for developing the proposed model will be demonstrated.

\subsection{Indicators of moisture supply}

\subsubsection{Drought indices selection}

The standardized precipitation index (SPI; McKee et al., 1993) was considered appropriate for this study for the following reasons. Precipitation is the only variable required in the SPI calculation, allowing this index to be applied in regions where the availability of weather data limits the use of other well-accepted indices, such as the Palmer drought severity index (PDSI). The SPI's unique characteristic, a wide spectrum of time scales, makes it more flexible for either short-term or long-term drought monitoring. In addition, the specification of a time scale in the definition of drought means that drought initiation, intensity, duration, magnitude, and ending are all dependent on a time scale and can be addressed by the SPI (McKee et al., 1993). Therefore, SPI values from very short time scales 
(e.g., 1 or 2 weeks) to long time scales (e.g., 48 to 52 weeks) more accurately reflect the amount, intensity, timing, and distribution of precipitation, which are more critical to crop growth than the value from a single time scale. Furthermore, the flexible time scales of the SPI make it easier to compute the index in order to match a crop's phenological cycle while providing the moisture supply status along with a crop's growth stages. The procedures for calculating the SPI can be found in Edwards and McKee (1997).

The crop-specific drought index (CSDI; Meyer et al., 1993) was chosen as a partner for the SPI in developing the proposed agricultural drought risk-assessment model. The CSDI was developed by integrating four critical factors: crop specificity, soil specificity, the ratio of water consumed by the crop to potential consumption, and the crop sensitivity during the growth stage in which water stress occurs. The CSDI was originally developed for corn (Meyer et al., 1993), and then extended to soybeans (Meyer and Hubbard, 1995), wheat (Xu, 1996), and sorghum (Camargo and Hubbard, 1999). Differences in CSDI values among crops are created by sensitivity coefficients applied to the respective major crop-growth stages.

The CSDI calculation requires three types of data: weather, soil, and crop phenology. Weather data include precipitation, maximum and minimum temperatures, dew-point temperature, wind speed, and solar radiation. It should be noted that most weather stations only measure precipitation and temperature. Therefore, dewpoint temperature, wind speed, and solar radiation were estimated from the existing maximum and minimum temperature records (Mahmood and Hubbard, 2002).

A soil file was created for each weather station to reflect the soil characteristics associated with the dominant agricultural soil in the respective county. Soil files contain initial water content, the saturation water content, field capacity content, and the wilting-point content for each layer of soil. In addition, some coefficients are given for the run-off curve and the drainage parameterization. Phenology data, used to determine crop maturation rates and growth cycles, consist of the beginning day, which is the day of the crop emergence, and the ending day, which is the day when the crop reaches maturity.

The CSDI links specific crop responses to drought, making it useful for the proposed crop-specific risk assessment model. In addition, one of the outputs of the CSDI calculation is the crop development cycle information based on each year's actual weather data. According to this output, the multiple time scales of the SPI can be linked to crop development cycles, accomplishing a drought risk assessment at each critical phenological stage. However, a limitation to the CSDI is that the data requirement for the CSDI calculation restricts its application to regions where appropriate weather data are available. In spite of this limitation, operational flexibility of this proposed drought risk-assessment model is not compromised because regions that intend to use this proposed model will either have the appropriate weather data or will use a modified model with indices tailored to that region.

Climatic data for 1971-2001 used in the calculation of drought indices were collected by the National Weather Service Cooperative Observer Network in Nebraska (HPRCC, 2003). 


\subsubsection{General variables selection}

The impact of water stress on yield is related to the precipitation amount, intensity, timing, and distribution. SPI values at high-frequency time scales reflect moisture supply more precisely than SPI values with lower frequency. As a result, the time scales of the SPI that were included in the study are: $1,2,3,4,5,6,7,8,9,10,11,12,14,16,18,20,22,24,26,28$, $30,32,36,40,44$, and 52 weeks. The total number of the SPI intervals is 26 .

The 26 SPI values cannot be used as individual variables in the proposed model for the following reasons. First, the information contained in the SPI values might overlap between values at very close time scales (e.g., 1 week and 2 week SPI values) if both were included. Second, the degrees of freedom will be too small if the 26 SPI values are included. The concept of degrees of freedom in statistics refers to "the number of independent estimates of the statistic of interest that could be obtained from a given dataset" (Taylor, 1990). Thus, the more variables involved, the less the degrees of freedom.

As a result, a few variables that describe the variation of the 26 SPI values are needed. Principal components analysis (PCA) is a useful tool for reducing the statistical interdependence of the climatic variables and retaining most of the variation of the original variables (Pochop et al., 1975; Dennett et al., 1980; Meyer et al., 1991).

The PCA was performed on the 26 SPI values. The number of principal components (PCs) retained is determined by the amount of total sample variance explained, and the relative sizes of the eigenvalues (the variances of the sample PCs). In this study, the criteria to retain PCs is that $90 \%$ of total variance is explained and that the size of the eigenvalue is greater than one. As a result, three PCs were retained.

Starr and Kostrow (1978) pointed out that although PCs account for most of the total variance, PCs of the climate variables "are not guaranteed to be the best predictors of yield. Crop plants could, in fact, be more sensitive to infrequently occurring anomaly sequences than they are to commonly occurring ones." From a statistical point of view, the first three PCs are able to explain $90 \%$ of the total variance of the 26 SPI values. However, it does not follow that the three PCs can explain $90 \%$ of biological effects that influence the crop growth. Actually, the three PCs represent overall drought conditions and contrasts between different drought time scales.

Thus, in addition to the three PCs, the SPI values at four time scales were selected as variables in the model development: 4 weeks, 10 weeks, 32 weeks, and 52 weeks. The SPI values at the four time scales represent the magnitude of drought at very short, short, medium, and long time periods respectively, which can be used to summarize the moisture supply from short to long time scales for a developing crop. The information contained in the four SPI values is not completely repeated by the PC factors. Therefore, the four SPI values and the first three PCs, as well as the CSDI, were selected as the general variables for further analysis in the study. 


\subsection{Indicator of agricultural drought risk and critical crop phenological times for risk assessment}

\subsubsection{Crop yields and yield residuals in leading counties}

As this study considers rain-fed crop yield to be an indicator of agricultural drought risk because of limited moisture supply before and during the growing season, and all the analyses were undertaken at a county level, county-level crop yield was required. The yields of nonirrigated corn (for grain) and soybeans of each county in Nebraska during 1971 to 2001 were obtained from the online database of the National Agricultural Statistics Service of the USDA (2003).

Although corn and soybeans are planted in most of Nebraska's counties, it is appropriate to focus on the counties that account for most of the harvest, referred to as the leading counties. For corn, the largest acreage and the highest production are in the northeast, east, and south-central areas. Soybean production is concentrated in the eastern areas of the state. The leading counties were selected by ranking the harvested acreage and keeping the counties with the highest acreage until $90 \%$ of the total state acreage harvested for rainfed corn during 1971-2001 was accounted for; counties associated with the other 10\% were not considered. The same procedure was used for soybeans. It was found that all the leading counties for soybeans were also leading counties for corn, but there were leading counties for corn that were not leading counties for soybeans. As a result, there were 42 counties for corn and 23 for soybeans, in a state with 93 counties. Each leading county has one or more weather stations. For the counties with more than one weather station, the drought indices of each station were calculated and then averaged into one value.

It was noticed that a marked upward trend in yields with time exists in all the counties for both corn and soybeans. This trend was the result of advances in agricultural technology (e.g., increases in rates of fertilizer application and use of new, higher yielding varieties; Starr and Kostrow, 1978; Dennett et al., 1980). The technological trend was defined to be a linear function of the year (Hill et al., 1980). In order to eliminate the bias due to the technological trend in yield, the yield was detrended by regressing it against the linear time trend variable. Furthermore, the residuals of the detrended yield were obtained because the residual variation reflects the effects of weather on yield (Dennett et al., 1980; da Mota, 1983), and the residuals amplify yield departures from normal, making the variability of yield more obvious. A positive yield residual means the yield is above the multipleyear average yield, whereas a negative residual means the yield is below the average yield. The bigger the absolute value of yield residual, the bigger the departure from the average yield.

\subsubsection{Definition of a drought-risk year}

Since this study was intended to investigate drought risk, it was necessary to identify a standard criterion to define drought-risk years based on the corresponding crop yields. The yield residuals are normally distributed with a mean of zero and variance of one. Thus, the probability of a yield residual below -0.5 is $30 \%$ (see table of standard normal distribution). This probability matches that of drought occurrence rates in the historical records (da Mota, 1983; McKee et al., 1993). Also, it is presumed that farmers will suffer economic 
losses if crop yield residuals are -0.5 or below. Therefore, a year is identified as a high drought-risk year when the corresponding crop yield residual (corn or soybeans) is below -0.5 . Otherwise, the year is a low-risk year. According to this criterion, the years of the study period were classified into two groups: high-risk and low-risk years.

\subsubsection{Identification of influential data}

It is necessary to identify subsets of the data used in the model development that appear to have a disproportionate influence on the estimated model. Such subsets of the data are called influential data or outliers. In this study, the criterion for judging the influential data is the consistency between the yield residuals and weather data (the SPI and CSDI) before and during the growing season. The regression diagnostics method was used to identify influential data. Five indicators of influential data were used to detect outliers: Student residual, Cook's D, hat-matrix diagonals, covariance ratio, and DIFFITS. The descriptions of these indictors can be found in Belsley et al. (1980) and Draper and Smith (1998). For each observation, if at least two indicators show that the observation is an outlier, then this observation will be excluded from the model development.

For instance, 1993 was a severe flood year in Nebraska: soils were extremely wet, and the weather was cooler than normal and cloudy. As a result, some corn was not planted or was replanted. Under this circumstance, the corn yields in 1993 were very poor, and the SPI values were extremely high. Also, the CSDI values indicated it was supposed to be a high-yield year because the CSDI model is not able to distinguish optimum moisture supply from moisture surplus. Therefore, the data in 1993 were identified as outliers.

\subsubsection{Critical phenological times to assess risk}

The impact of moisture stress on crop yield is determined by the phenological timing of the stress. The aim of this study was to assess drought risk at critical phenological times before and during the growing season. Crop sensitivity coefficients in the CSDI are addressed in four combined growth periods for corn and five for soybeans, based on the research conducted on the effects of water stress on crops. Besides the four periods defined in the CSDI for corn (vegetative, ovule, reproduction, and ripening) and the five periods for soybeans (vegetative, blooming, pod formation, pod fill, and ripening), this study defined one more period for both corn and soybeans, i.e., preplant, which was the 1 year period before crop emergence. Although the recharge period begins in September or October, there is the question of how much water the crop from the previous season used and whether this affected the recharge. Thus, input variables for the 1 year preplant period were all tested for their contribution.

The CSDI is able to simulate the dates of each stage based on the real-time weather and phenology data of a year for each weather station. Because of variable weather, the actual dates of each growth stage change from year to year, as well as from county to county across the state. It was found that most of the leading counties in corn and soybeans are clustered in eastern Nebraska. Weather and phenology data are not significantly different among the leading counties. In addition, it is easier to produce a state risk map if the same date is used for each stage. As a result, the frequencies of the dates of each stage during 1971-2001 were calculated and the most frequent dates associated with each stage are 
shown in tables I and II for corn and soybeans respectively. In the following discussions, for corn, preplanting denotes the period before corn emergence; stage 1 denotes vegetative period; stage 2, ovule; stage 3, reproduction; and stage 4, ripening. The same case holds true for soybeans, using preplanting and stages 1 through 5 to denote the period before soybean emergence and the five periods. The timing of the risk assessment will be based on these critical phenological times.

\begin{tabular}{ll}
\hline \multicolumn{2}{l}{ Table I. The critical phenological times to assess risk for corn } \\
\hline Critical time & Date \\
\hline Preplanting & 17th week (29 April in a nonleap year) \\
Vegetative (stage 1) & 26th week (1 July in a nonleap year) \\
Ovule (stage 2) & 29th week (22 July in a nonleap year) \\
Reproduction (stage 3) & 33rd week (19 August in a nonleap year) \\
Ripening (stage 4) & 39th week (30 September in a nonleap year) \\
\hline & \\
\hline Table II. The critical phenological times to assess risk for soybeans \\
\hline Critical time & Date \\
\hline Preplanting & 19th week (13 May in a nonleap year) \\
Vegetative (stage 1) & 26th week (1 July in a nonleap year) \\
Bloom (stage 2) & 28th week (15 July in a nonleap year) \\
Pod formation (stage 3) & 32nd week (12 August in a nonleap year) \\
Pod Fill (stage 4) & 35th week (2 September in a nonleap year) \\
Ripening (stage 5) & 40th week (7 October in a nonleap year) \\
\hline
\end{tabular}

\subsection{Risk-assessment model development}

\subsubsection{Rationale for model development}

This study assumed that the crop yield was only influenced by the weather before and during the growing season, and that other factors, such as insects and disease, were stable. The weather during the growing season may influence drought-risk impacts on yield directly, whereas preplanting weather indirectly affects the risk impacts on yield through pests, soil moisture conditions, and its correlation with the weather during the growing season (Luo et al., 1994). This study's aim was to establish a predictable relationship between the indicators of moisture supply and the indicator of the impact of the moisture supply on agriculture. The indicators of moisture supply were represented by the SPI values and the CSDI, whereas the indicator of impact on yield was represented by two categorical variables: low- and high-risk years. As mentioned previously, a year is a high-risk year if the corresponding yield residual (corn or soybeans) is smaller than -0.5 . Otherwise, it is a low-risk year.

From a statistical point of view, this is a case of categorical dependent variables (i.e., low- and high-risk years) and a set of independent variables (the SPI values at the four time scales, PCs and CSDI). The goal is to assign a year of interest to one of the two previ- 
ously defined groups in terms of drought risk according to the known SPI and CSDI. Discriminant analysis is a statistical technique for classifying individuals or objects into mutually exclusive and exhaustive groups through a set of independent variables (Johnson and Wichern, 1998). Dillon and Goldstein (1984) defined discriminant analysis as "deriving linear combinations of a set of independent variables that will discriminate between the $a$ priori defined groups in such a way that the misclassification error rates are minimized." Luo et al. (1994) used this method to develop a yield-discriminant model from historical weather data. Based on the model, an unknown yield can be assigned either a high- or lowyield group using forecasted weather data.

In this study, we wish to discriminate between the low-risk and high-risk groups relative to agricultural production based on the SPI and CSDI variables. On the basis of historical data, therefore, a classification rule can be derived through analyzing the relationships between the two groups and their associated SPI and CSDI. Then the rule can be used to assign new objects optimally to the predefined groups.

\subsubsection{Risk-assessment model development for corn and soybeans}

The procedures to construct an agricultural drought risk-assessment model based on the weather are as follows. The historical SPI and CSDI variables were assigned to two groups: the variables in the first group were from the labeled low-risk years based on the yield residuals; those in the second group were from the labeled high-risk years. Then, two discriminant analysis techniques were performed on each selected critical phenological time, with the goal of assessing drought risk from each of the growth stages. The first one was canonical discriminant analysis, which is a dimension-reduction technique similar to PCs

and canonical correlation. Canonical discriminant analysis derives a linear combination of the SPI and CSDI variables that best summarize the differences between the two groups and defines the uncorrelated first and second canonical variables based on the linear combination. By plotting the first versus second canonical variables, it is possible to visualize how well the SPI and CSDI variables discriminate between the low- and high-risk groups.

The second discriminant analysis technique was classificatory discriminant analysis, which develops a linear discriminant function or classification criterion on the basis of maximizing the multivariate standard distance between the two groups, and then classifies observations into the two known groups on the basis of the SPI and CSDI variables. The discriminant function was estimated using the discriminant procedure within SAS. Based on the discriminant function derived, the means of the discriminant function in the lowand high-risk groups were calculated by multiplying the discriminant weight associated with each variable by the variable's mean and then summing these products. Then the midpoint between the two groups was obtained by averaging the two means obtained. For a new observation, a discriminant score obtained based on the discriminant function indicates whether the observation would be grouped into either a low-risk or a high-risk year, depending upon whether the score falls to the right or left of the midpoint.

Although the seven SPI variables (four SPI values and three PCs) and the CSDI were determined to be the general variables for each critical time period by considering the information included from both biological and statistical points of view, they are likely to be 
correlated somehow and may contain overlapping pieces of information. Redundant information may impair the ability to assess risk correctly for future observations (Flury, 1997), which was proved by tests in this study. In each stage, tests were conducted to decide which particular subset of the general variables should be used for the development of the risk-assessment model and which of the variables can be viewed as being redundant in the presence of this subset of variables. The test to determine whether a variable would be kept at each critical time period hinged on the performance of that variable in the discriminant analysis. The final variables used in the discriminant analyses were determined on the test results and varied from one critical stage to another. As the crop develops, the variables from a previous time may be retained, the variables from the current time may be added, and the variables that contain redundant information may be removed.

Specifically, for preplant of corn and soybeans, the CSDI values are not available. Thus, only SPI variables can be used. The tests demonstrated that the SPI values at the four time scales and the first PC were the optimal combination in the discriminant analysis. For stage 1 , in addition to the variables used at the preplanting, the four SPI values, the three PCs and the CSDI of the current stage were added. For later stages, the earlier stages' variables were removed because their impacts on the final yield become weak. Corn and soybeans exhibit different sensitivities to water stress, so the variables used at later stages are slightly different. For the last stage of corn, for instance, the SPI values at the four time scales from stages 2 to 4 , the first PC from preplanting to stage 3, the three PCs of stage 4 , and the CSDI of stage 4 were used. For soybeans, only the SPI values from stages 3 to 5 , the first PCs from stages 2 to 5 , and the CSDI of the last stage were retained. Lists of the final variables used in each stage for corn and soybeans are shown in tables III and IV respectively.

\begin{tabular}{|c|c|c|c|c|c|}
\hline Variable $^{a}$ & $\begin{array}{l}\text { Preplanting } \\
\text { (17th week) }\end{array}$ & $\begin{array}{c}\text { Stage } 1 \\
\text { (26th week) }\end{array}$ & $\begin{array}{c}\text { Stage } 2 \\
\text { (29th week) }\end{array}$ & $\begin{array}{c}\text { Stage } 3 \\
\text { (33rd week) }\end{array}$ & $\begin{array}{c}\text { Stage } 4 \\
\text { (39th week) }\end{array}$ \\
\hline 4-week SPI of 17 th week & $\checkmark$ & $\checkmark$ & $\checkmark$ & & \\
\hline 10-week SPI of 17 th week & $\checkmark$ & $\checkmark$ & $\checkmark$ & & \\
\hline 32-week SPI of 17th week & $\checkmark$ & $\checkmark$ & $\checkmark$ & & \\
\hline 52-week SPI of 17th week & $\checkmark$ & $\checkmark$ & $\checkmark$ & & \\
\hline 4-week SPI of 26th week & & $\checkmark$ & $\checkmark$ & $\checkmark$ & $\checkmark$ \\
\hline 10-week SPI of 26th week & & $\checkmark$ & $\checkmark$ & $\checkmark$ & $\checkmark$ \\
\hline 32-week SPI of 26th week & & $\checkmark$ & $\checkmark$ & $\checkmark$ & $\checkmark$ \\
\hline 52-week SPI of 26th week & & $\checkmark$ & $\checkmark$ & $\checkmark$ & $\checkmark$ \\
\hline 4-week SPI of 29th week & & & $\checkmark$ & $\checkmark$ & $\checkmark$ \\
\hline 10-week SPI of 29th week & & & $\checkmark$ & $\checkmark$ & $\checkmark$ \\
\hline 32-week SPI of 29th week & & & $\checkmark$ & $\checkmark$ & $\checkmark$ \\
\hline 52-week SPI of 29th week & & & $\checkmark$ & $\checkmark$ & $\checkmark$ \\
\hline 4-week SPI of 33rd week & & & & $\checkmark$ & $\checkmark$ \\
\hline 10-week SPI of 33rd week & & & & $\checkmark$ & $\checkmark$ \\
\hline 32-week SPI of 33rd week & & & & $\checkmark$ & $\checkmark$ \\
\hline 52-week SPI of 33rd week & & & & $\checkmark$ & $\checkmark$ \\
\hline
\end{tabular}




\begin{tabular}{|c|c|c|c|c|c|}
\hline 4-week SPI of 39th week & & & & & $\checkmark$ \\
\hline 10-week SPI of 39th week & & & & & $\checkmark$ \\
\hline 32-week SPI of 39th week & & & & & $\checkmark$ \\
\hline 52-week SPI of 39th week & & & & & $\checkmark$ \\
\hline First PC of 17th week & $\checkmark$ & $\checkmark$ & $\checkmark$ & $\checkmark$ & $\checkmark$ \\
\hline \multicolumn{6}{|l|}{ Second PC of 17th week } \\
\hline \multicolumn{6}{|l|}{ Third PC of 17th week } \\
\hline First PC of 26th week & & $\checkmark$ & $\checkmark$ & $\checkmark$ & $\checkmark$ \\
\hline Second PC of 26th week & & $\checkmark$ & & & \\
\hline Third PC of 26th week & & $\checkmark$ & & & \\
\hline First PC of 29th week & & & $\checkmark$ & $\checkmark$ & $\checkmark$ \\
\hline Second PC of 29 th week & & & $\checkmark$ & & \\
\hline Third PC of 29th week & & & $\checkmark$ & & \\
\hline First PC of 33rd week & & & & $\checkmark$ & $\checkmark$ \\
\hline Second PC of 33rd week & & & & $\checkmark$ & \\
\hline Third PC of 33rd week & & & & $\checkmark$ & \\
\hline First PC of 39th week & & & & & $\checkmark$ \\
\hline Second PC of 39th week & & & & & $\checkmark$ \\
\hline Third PC of 39th week & & & & & $\checkmark$ \\
\hline CSDI of 26th week & & $\checkmark$ & $\checkmark$ & & \\
\hline CSDI of 29th week & & & $\checkmark$ & & \\
\hline CSDI of 33rd week & & & & $\checkmark$ & \\
\hline CSDI of 39th week & & & & & $\checkmark$ \\
\hline
\end{tabular}

a. 4-week SPI of 17 th week denotes the SPI value at 4 -week time scale of the 17 th week. First PC of 17 th week denotes the first PC of the 17th week's SPI values. CSDI of 26th week denotes the CSDI value of the 26th week, and so on.

Table IV. Variables used in the discriminant analysis at each critical phenological time for soybeans

\begin{tabular}{lcccccc}
\hline Variable & $\begin{array}{c}\text { Preplanting } \\
\text { (19th week) }\end{array}$ & $\begin{array}{c}\text { Stage 1 } \\
\text { (26th week) }\end{array}$ & $\begin{array}{c}\text { Stage 2 } \\
\text { (28th week) }\end{array}$ & $\begin{array}{c}\text { Stage 3 } \\
\text { (32nd week) }\end{array}$ & $\begin{array}{c}\text { Stage 4 } \\
\text { (35th week) }\end{array}$ & $\begin{array}{c}\text { Stage 5 } \\
\text { (40th week) }\end{array}$ \\
\hline 4-week SPI of 19th week & $\checkmark$ & $\checkmark$ & $\checkmark$ & $\checkmark$ & \\
10-week SPI of 19th week & $\checkmark$ & $\checkmark$ & $\checkmark$ & $\checkmark$ & \\
32-week SPI of 19th week & $\checkmark$ & $\checkmark$ & $\checkmark$ & $\checkmark$ & \\
52-week SPI of 19th week & $\checkmark$ & $\checkmark$ & $\checkmark$ & $\checkmark$ & $\checkmark$ \\
\hline 4-week SPI of 26th week & & $\checkmark$ & $\checkmark$ & $\checkmark$ & $\checkmark$ \\
10-week SPI of 26th week & & $\checkmark$ & $\checkmark$ & $\checkmark$ & $\checkmark$ \\
32-week SPI of 26th week & & $\checkmark$ & $\checkmark$ & $\checkmark$ & $\checkmark$ \\
52-week SPI of 26th week & & $\checkmark$ & $\checkmark$ & $\checkmark$ & $\checkmark$ \\
\hline 4-week SPI of 28th week & & & $\checkmark$ & $\checkmark$ & $\checkmark$ \\
10-week SPI of 28th week & & & $\checkmark$ & $\checkmark$ & $\checkmark$ \\
32-week SPI of 28th week & & & $\checkmark$ & $\checkmark$ & $\checkmark$ \\
52-week SPI of 28th week & & & & $\checkmark$ & $\checkmark$ \\
\hline
\end{tabular}


Wu, Hubbard, And Wilhite, international Journal of Climatology 24 (2004)

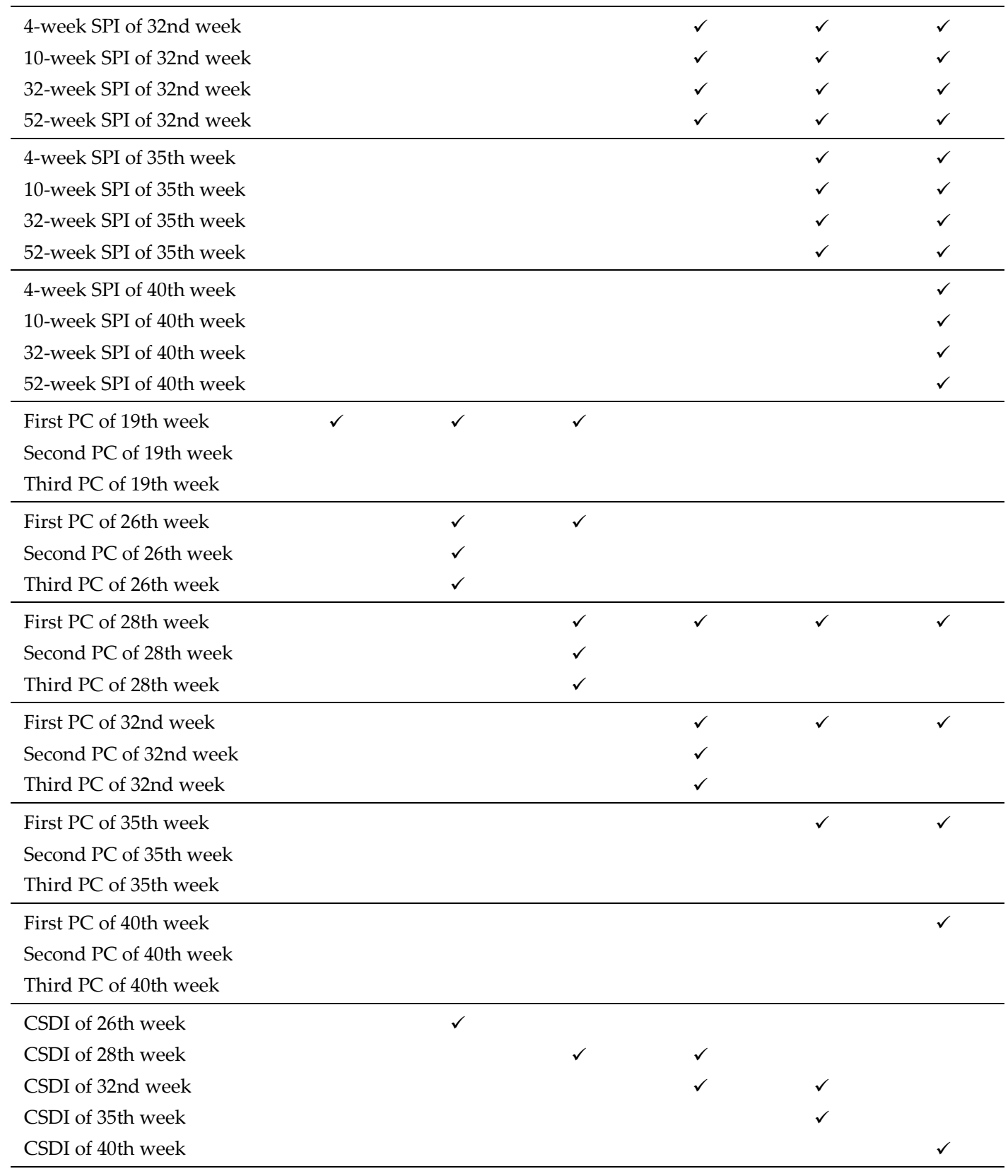

a. For definitions see table III footnote. 
The discriminant function form of the risk-discriminant model, for example, for corn preplanting is

$$
\begin{aligned}
& D=\beta_{1}\left(\mathrm{SPI}_{1} 7^{-4 \mathrm{w}}\right)+\beta_{2}\left(\mathrm{SPI}_{1} 7^{-10 \mathrm{w}}\right)+\beta_{3}\left(\mathrm{SPI}_{1} 7^{-32 \mathrm{w}}\right) \\
& +\beta_{4}\left(\mathrm{SPI}_{17}{ }^{52 \mathrm{w}}\right)+\beta_{5}\left(\mathrm{PC}_{17}\right)+C
\end{aligned}
$$

where $D$ is the discriminant score; $\mathrm{SPI}_{1} 7^{-4 \mathrm{w}}$ is the SPI value at 4 weeks of 17 th week; $\mathrm{PC}_{17}$ is the first PC of the 17th week's SPI values, and so on; $\beta$ is the discriminant function weight, and $C$ is the intercept.

The discriminant function forms for other growth stages of both corn and soybeans were similar, but the variables change, as tables III and IV indicate. The discriminant function weights were compared between corn and soybeans in the approximate corresponding stages. Thus, the differences of the contribution of each variable to the discriminant score between the two crops are clear.

\subsubsection{Validation of the risk-assessment model}

The validation of the risk-assessment model was accomplished in three ways:

First, the model was derived by the data of 38 out of 42 leading counties for each stage for corn, and by the data of 21 out of 23 leading counties for soybeans during 1971-2001 (the dataset used to derive the model is called the training dataset). Then the model was validated by the data of the remaining counties during the same period (the dataset used to validate the model is called the test dataset). Each observation of the test dataset was classified at each phenological stage on the basis of the discriminant function and classification rule derived by the training dataset. The counties used for the validation were randomly selected within the study area. In order to compare the model outputs of corn and soybeans more effectively, the test dataset for soybeans was from two out of the four counties of the corn test dataset. The results derived by the model for the test dataset from preplanting to stage 4 for corn (to stage 5 for soybeans) were compared with the predefined groups to evaluate the performance of the model.

In the first validation of the model, both training and test datasets were from the period 1971-2001. Although the test dataset was not directly used in model development, intercorrelation exists between the training and test datasets because geographically close counties usually experience similar weather and crop response. Therefore, it is necessary to evaluate the performance of the model using a set of independent data, i.e., a dataset from new years. Although weather in new years is somewhat related to historical weather, the relationship is weaker. Therefore, the second way to validate the model was to use the training dataset during 1971 to 1995, and the test dataset during 1996 to 2000 for both corn and soybeans.

Third, the model was validated by assessing drought risk for both corn and soybeans in a few severe drought years (1974 and 1980) and a dry-wet mixed year (2001) in order to evaluate the performance further and demonstrate the application of the risk-assessment model. The results of risk assessment for 2002 were also presented. Agricultural drought risk-assessment maps for 2002 corn at each of the five stages were created for Nebraska 
and presented in ArcGIS 8.2 (Environmental Systems Research Institute, Inc.) to provide a better visualization of agricultural drought risk assessment.

\section{Results and Discussion}

\subsection{Results of discriminant analyses}

\subsubsection{Canonical discriminant analysis}

First, canonical discriminant analysis was performed on the discriminant variables selected previously for each stage (tables III and IV). For each stage of both corn and soybeans, the first and second canonical variables were obtained and plotted by running the CANDISC procedure within SAS.

Figures 1 and 2 show the plots of canonical variables of each stage for corn and soybeans respectively. For corn at preplanting, visual analysis suggests that the first and second canonical variables do not separate the observations from the two groups effectively. Overlap between the low- and high-risk groups is significant. At stage 1, however, some of the observations that belong to the high-risk group are separated clearly from the majority of the observations. At stage 2, more observations from the two groups are separated in the two opposite directions. As the growth period progresses, the separation between the two groups becomes more obvious. The observations from the high-risk group mostly cluster on the left side of the plots, whereas the observations from the low-risk group cluster on the right side. 

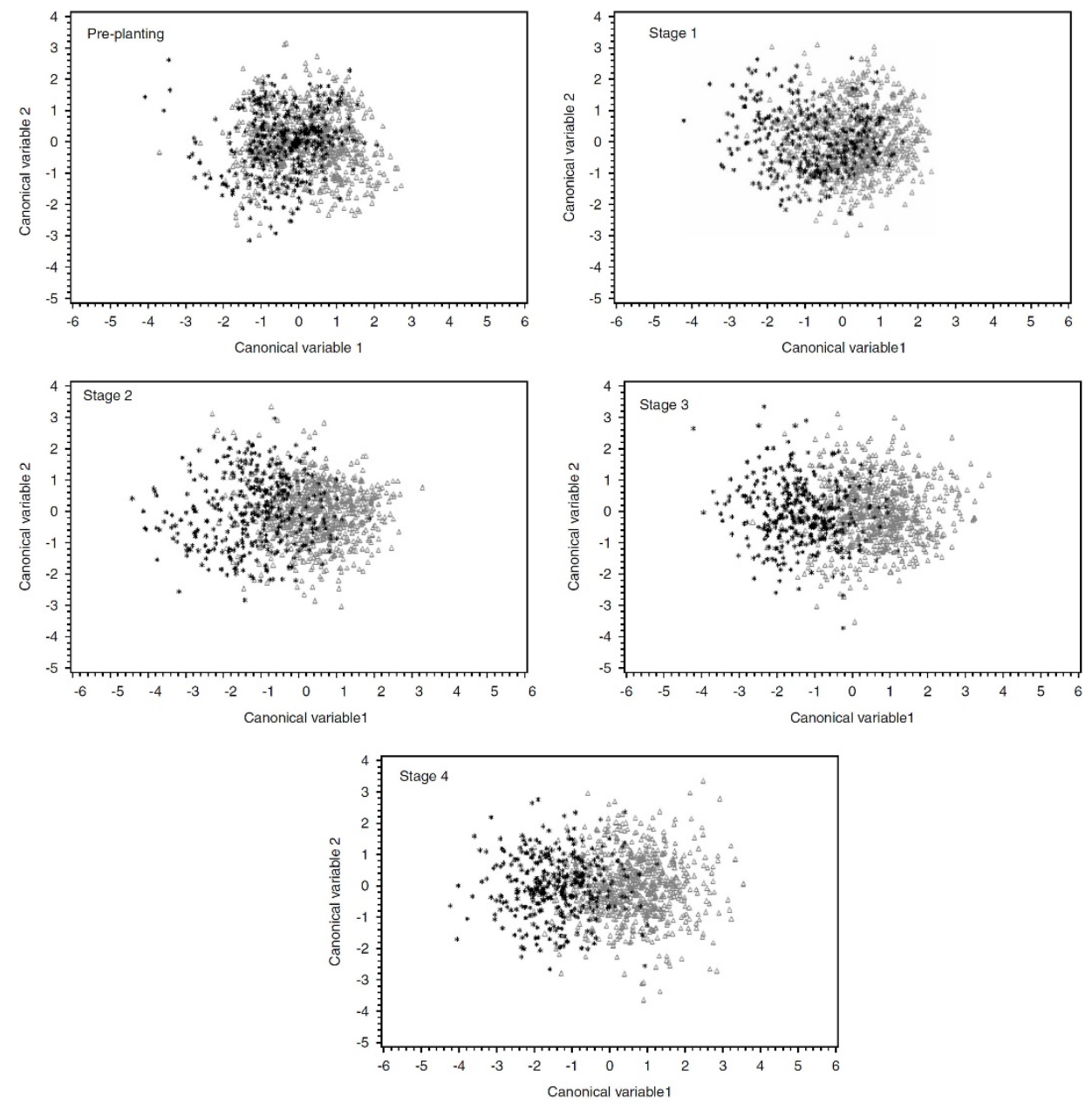

Figure 1. Plots of the first versus second canonical variables at preplanting through to stage 4 for corn. Black stars denote high-risk year; gray triangles denote low-risk year. Canonical variable 1 is the first canonical variable and canonical variable 2 is the second one.

For soybeans (fig. 2), points on the plots of the first versus second canonical variables appear sparser because the observations of soybeans in the training dataset were less than those of corn (there were 590 observations for soybeans, and 1211 for corn). This visual effect makes it harder to observe the tendency of separation. It can also be seen that the separation is not as good as it was with corn. This can be explained by the fact that soybeans are not as sensitive to weather as corn; thus, separation on the basis of the SPI and CSDI is relatively difficult. The tendency of separation becomes clearer from stage 3 on. 

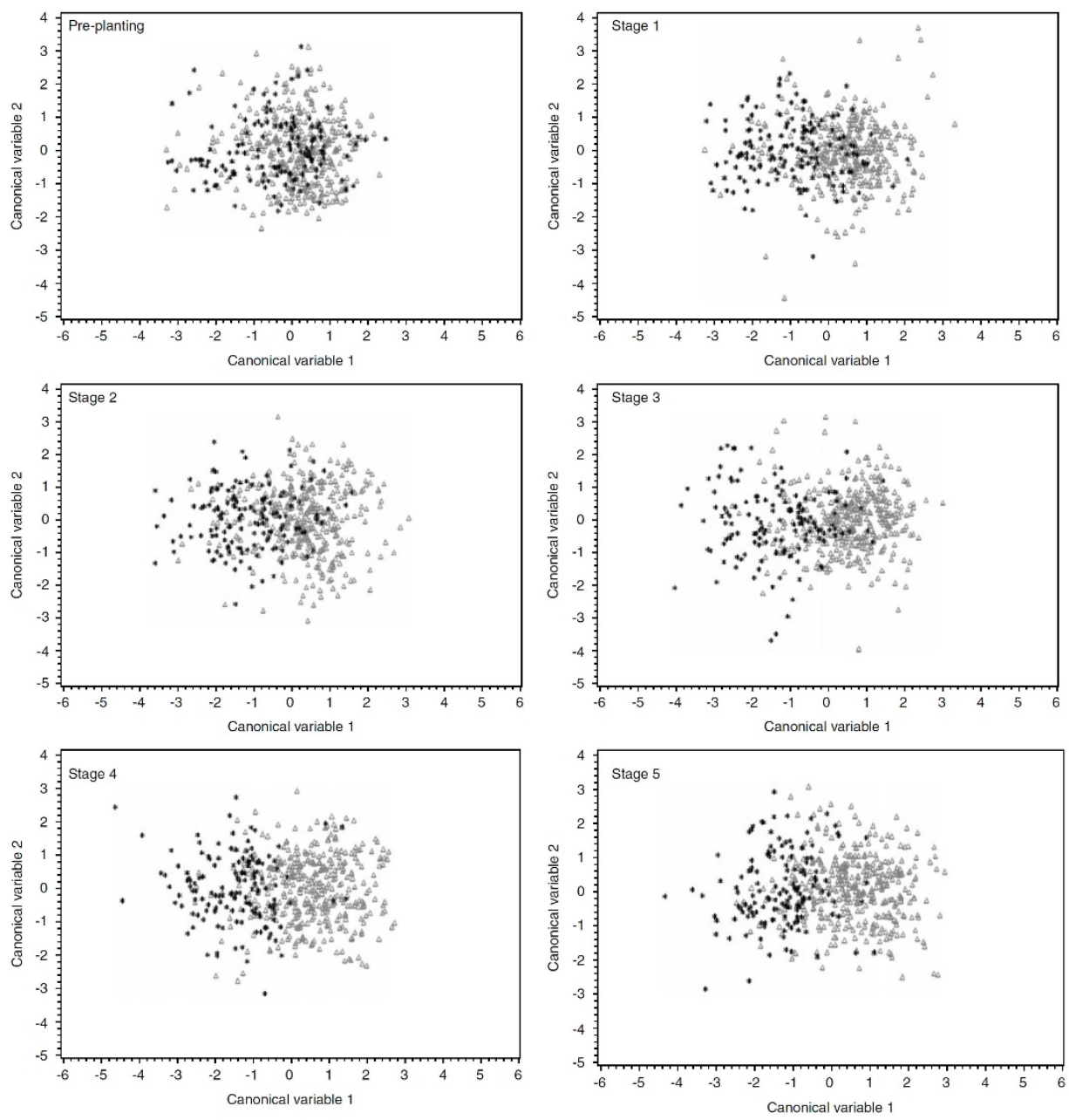

Figure 2. Plots of the first versus second canonical variables at preplanting through to stage 5 for soybeans. Black stars denote high-risk year; gray triangles denote low-risk year. Canonical variable 1 is the first canonical variable and canonical variable 2 is the second one.

Therefore, based on the canonical discriminant analysis, it is possible to discriminate the high-risk group from the low-risk group on the basis of the selected variables derived from the SPI and CSDI for both corn and soybeans at later stages. Of course, it is anticipated that the discrimination for corn is easier than that for soybeans. Through the classificatory discriminant analysis, a classification rule will be established. Consequently, a risk-assessment model will be developed and can be applied to new observations.

\subsubsection{Classificatory discriminant analysis}

Classificatory discriminant analysis was performed on the selected variables of each stage for each crop from the training dataset. The linear discriminant functions of each stage for 
each crop were derived by running the DISCRIM procedure within SAS. For example, the linear discriminant function derived (refer to equation (1)) for preplanting corn is

$$
\begin{aligned}
D= & 0.07\left(\mathrm{SPI}_{1} 7^{-4 \mathrm{w}}\right)+1.16\left(\mathrm{SPI}_{1} \tau^{-10 \mathrm{w}}\right)+0.03\left(\mathrm{SPI}_{1} \tau^{-32 \mathrm{w}}\right) \\
& +0.29\left(\mathrm{SPI}_{1} 7^{-52 \mathrm{w}}\right)-0.2\left(\mathrm{PC}_{17}\right)+0.05
\end{aligned}
$$

where previous definitions hold and the coefficients are discriminant function weights associated with each variable.

With the discriminant function, the means of the discriminant function in the low- and high-risk groups and the midpoint of separation between the two groups were calculated for each stage. For instance, the means of preplanting for corn derived from equation (2) were 0.165 for the low-risk group and -0.165 for the high-risk group. Thus, the midpoint between the two groups was zero. Actually, the midpoint with zero was not a coincidence, because the discriminant function was transformed to a form convenient for classification purposes by adding a constant (the intercept in equation (1) and 0.05 in equation (2)). Hence, the classification rule of stage 1 for corn is: assign an observation to the low-risk group if $D>0$, and to the high-risk group if $D<0$. $D$ is the discriminant score of the observation, which can be calculated based on equation (2).

Comparing the discriminant function weights between corn and soybeans, it was found that the variables that contribute the most to the discrimination analysis are similar between the two crops at each stage. At preplanting, for corn, the discriminant weight of $\mathrm{SPI}_{1} 7^{-10 \mathrm{w}}$ dominates the function. For soybeans, the weight of $\mathrm{SPI}_{1} 7^{32 \mathrm{w}}$ dominates the func-

tion. From stages 1 to 4 for corn, generally, the SPI value at 32 weeks of the current stage dominates the function, followed by the SPI values at 32 weeks of the previous stages, the first PC and CSDI of the current stage. Similarly, from stages 1 to 3 for soybeans, the SPI value at 32 weeks of the current stage dominates the function, followed by the SPI values at 32 weeks of the previous stages. At stages 4 and 5, however, only the SPI values at 32 weeks of the previous stage(s) have significant weights, indicating that the crop condition has been established and is not affected significantly by the variables of the current stages.

\subsection{Results of validation of the risk-assessment model}

The performance of the risk-assessment model was validated by estimating error rates (probabilities of misclassification) with the three kinds of test dataset. Error rates indicate the variability unexplained by the model, the degree to which the current input data departs from the data used to derive the model, and the quality of the current input data (Hill et al., 1980).

\subsubsection{Using the test dataset during 1971-2001 and 1996-2000}

The error rates are shown in tables V and VI for corn and soybeans respectively. The error rates are shown in this way: at preplanting for corn using the test dataset 1971-2001, for instance, 49 out of 116 observations are correctly assigned into the low-risk group based on the model, 18 are correctly assigned into the high-risk group, 33 are incorrectly assigned into the high-risk group, and 16 are incorrectly assigned into the low-risk group. Therefore, 
the error rate for the low-risk classification at preplanting is $40.2 \%$, and the high-risk classification error rate is $47.1 \%$.

Table V. Error rates of the risk assessments for the test dataset from the periods 1971-2001 and 1996-2000 for corn ${ }^{\mathrm{a}}$

\begin{tabular}{|c|c|c|c|c|c|c|c|}
\hline \multicolumn{2}{|c|}{ Validation period } & \multicolumn{3}{|c|}{ 1971-2001 } & \multicolumn{3}{|c|}{$1996-2000$} \\
\hline \multirow[b]{2}{*}{ Stage } & \multirow[b]{2}{*}{ From } & \multicolumn{2}{|c|}{ Classified into } & \multirow[b]{2}{*}{$\begin{array}{c}\text { Error rate } \\
(\%)\end{array}$} & \multicolumn{2}{|c|}{ Classified into } & \multirow[b]{2}{*}{$\begin{array}{c}\text { Error rate } \\
(\%)\end{array}$} \\
\hline & & $\begin{array}{l}\text { Low } \\
\text { risk }\end{array}$ & $\begin{array}{l}\text { High } \\
\text { risk }\end{array}$ & & $\begin{array}{l}\text { Low } \\
\text { risk }\end{array}$ & $\begin{array}{l}\text { High } \\
\text { risk }\end{array}$ & \\
\hline \multirow[t]{2}{*}{ Preplanting } & Low risk & 49 & 33 & 40.2 & 50 & 29 & 36.7 \\
\hline & High risk & 16 & 18 & 47.1 & 16 & 17 & 48.9 \\
\hline \multirow[t]{2}{*}{ Stage I } & Low risk & 61 & 21 & 25.6 & 58 & 21 & 26.6 \\
\hline & High risk & 11 & 23 & 32.4 & 9 & 24 & 27.3 \\
\hline \multirow[t]{2}{*}{ Stage 2} & Low risk & 68 & 14 & 17.1 & 65 & 14 & 17.7 \\
\hline & High risk & 6 & 28 & 17.7 & 6 & 27 & 18.2 \\
\hline \multirow[t]{2}{*}{ Stage 3} & Low risk & 74 & 8 & 9.8 & 71 & 8 & 10.1 \\
\hline & High risk & 3 & 31 & 8.8 & 3 & 30 & 9.1 \\
\hline \multirow[t]{2}{*}{ Stage 4} & Low risk & 73 & 9 & 11.0 & 73 & 6 & 7.6 \\
\hline & High risk & 3 & 35 & 8.8 & 3 & 30 & 9.1 \\
\hline
\end{tabular}

a. At preplanting for the test period of 1971-2001, 49 out of 116 observations are correctly assigned into the low-risk group, 18 are correctly assigned into the high-risk group, 33 are incorrectly assigned into the highrisk group, and 16 are incorrectly assigned into the low-risk group. The error rate of the low-risk classification at preplanting is $40.2 \%$, and that of the high-risk classification is $47.1 \%$.

Table VI. Error rates of the risk assessments for the test dataset from the periods 1971-2001 and 1996-2000 for soybeans

\begin{tabular}{|c|c|c|c|c|c|c|c|}
\hline \multicolumn{2}{|c|}{ Validation period } & \multicolumn{3}{|c|}{ 1971-2001 } & \multicolumn{3}{|c|}{ 1996-2000 } \\
\hline \multirow[b]{2}{*}{ Stage } & \multirow[b]{2}{*}{ From } & \multicolumn{2}{|c|}{ Classified into } & \multirow[b]{2}{*}{$\begin{array}{c}\text { Error rate } \\
(\%)\end{array}$} & \multicolumn{2}{|c|}{ Classified into } & \multirow[b]{2}{*}{$\begin{array}{c}\text { Error rate } \\
(\%)\end{array}$} \\
\hline & & $\begin{array}{l}\text { Low } \\
\text { risk }\end{array}$ & $\begin{array}{l}\text { High } \\
\text { risk }\end{array}$ & & $\begin{array}{l}\text { Low } \\
\text { risk }\end{array}$ & $\begin{array}{l}\text { High } \\
\text { risk }\end{array}$ & \\
\hline \multirow[t]{2}{*}{ Preplanting } & Low risk & 26 & 13 & 33.3 & 58 & 46 & 44.2 \\
\hline & High risk & 5 & 8 & 38.5 & 4 & 22 & 15.4 \\
\hline \multirow[t]{2}{*}{ Stage I } & Low risk & 31 & 8 & 20.5 & 84 & 20 & 19.2 \\
\hline & High risk & 5 & 8 & 38.5 & 16 & 10 & 61.5 \\
\hline \multirow[t]{2}{*}{ Stage 2} & Low risk & 31 & 8 & 20.5 & 84 & 20 & 19.2 \\
\hline & High risk & 4 & 9 & 30.8 & 10 & 16 & 38.5 \\
\hline \multirow[t]{2}{*}{ Stage 3} & Low risk & 32 & 7 & 18.0 & 81 & 23 & 22.1 \\
\hline & High risk & 4 & 9 & 30.1 & 5 & 21 & 19.2 \\
\hline \multirow[t]{2}{*}{ Stage 4} & Low risk & 34 & 5 & 12.8 & 82 & 22 & 21.2 \\
\hline & High risk & 3 & 10 & 23.1 & 4 & 22 & 15.4 \\
\hline \multirow[t]{2}{*}{ Stage 5} & Low risk & 33 & 6 & 15.4 & 80 & 24 & 23.8 \\
\hline & High risk & 2 & 11 & 15.4 & 2 & 24 & 7.7 \\
\hline
\end{tabular}


For corn, the error rates of the test datasets from 1971-2001 and 1996-2000 are close to each other from preplanting through to stage 4 , and the error rates generally decrease as the growth stages progress. At stage 1, the average error rate for the high- and low-risk classifications based on the two test datasets is about $28 \%$. At stage 2 , the average error rate falls to $17 \%$. In other words, the correct assessment possibility is $83 \%$ at stage 2 . The correct assessment possibility increases to $91 \%$ at stages 3 and 4 .

Because the test dataset during 1971-2001 for soybeans was from two of the four counties for corn, corn and soybeans were experiencing similar weather conditions during developmental stages. It is interesting to compare the performance of the model for the two crops under the same circumstances. Like corn, the error rates for soybeans decrease as the crop develops. However, the error rates in both the high- and low-risk classifications of soybeans are higher than those of corn at most of the approximate corresponding stages, indicating that the relationship between soybean yield and weather is not as strong as it was for corn.

\subsubsection{Validating in individual years}

The corn yield residuals of 1974 were all below -0.5 , meaning that corn yields of all the leading counties belonged to the high-risk group in this year. At preplanting (end of April), 13 out of the 42 leading counties were assigned to the high-risk group. From stage 1 (end of June) through to the last stage, all but two of the leading counties were classified in the high-risk group, with only $4.8 \%$ error rate. The error rates for 1980 corn indicated that the assessments at all stages were accurate. However, the error rates for 2001 corn were considerable, because only half of the 11 observations from the high-risk group were successfully classified at all the stages.

For soybeans, the error rates of the three individual years are generally higher than those for corn. 


\subsubsection{Average accuracy rates for corn and soybeans}

Tables VII and VIII show the average accuracy rates, converted from the error rates, of the risk assessment based on the three different kinds of test dataset for corn and soybeans.

Table VII. Average accuracy rates of the risk assessments of the three different kinds of test dataset for corn

\begin{tabular}{llcc}
\hline Stage & Risk group & Accuracy rates of each group $(\%)$ & Average accuracy rate $(\%)$ \\
\hline Preplanting & Low & 59.8 & \\
& High & 59.4 & \\
Stage 1 & Low & 77.8 & 76.0 \\
& High & 74.3 & \\
Stage 2 & Low & 83.5 & 85.1 \\
& High & 86.6 & \\
Stage 3 & Low & 89.7 & 88.7 \\
& High & 87.6 & \\
Stage 4 & Low & 89.2 & 89.1 \\
& High & 89.1 & \\
\hline
\end{tabular}

Table VIII. Average accuracy rates of the risk assessments of the three different kinds of test dataset for soybeans

\begin{tabular}{llcc}
\hline Stage & Risk group & Accuracy rates of each group (\%) & Average accuracy rate (\%) \\
\hline Preplanting & Low & 59.6 & \\
& High & 73.8 & 66.7 \\
Stage 1 & Low & 78.9 & 67.3 \\
& High & 55.7 & \\
Stage 2 & Low & 72.1 & 72.1 \\
& High & 68.9 & \multirow{2}{*}{80.4} \\
Stage 3 & Low & 77.1 & \\
& High & 83.6 & 82.5 \\
Stage 4 & Low & 78.1 & 80.6 \\
& High & 86.9 & \\
Stage 5 & Low & 75.9 & \\
& High & 85.2 & \\
& & & \\
\hline
\end{tabular}

It was not a surprise that the accuracy rates are lower at preplanting than that the later stages for both corn and soybeans because weather yet to occur during the growing season is uncertain at this time. However, there is a $60 \%$ or higher possibility of successfully assessing drought risk on dryland corn and soybean yield before the growing season, indicating that preplanting weather does have an impact on the crops' final yield. Some researchers forecasted yield at very early growth stages using "combined information," which was the actual preplanting weather data combined with the historical growingseason weather data, or combined with the growing-season weather forecast data (Duchon, 1986; Luo et al., 1994). Using weather data for preplanting alone to assess drought 
risk on the crop's final yield had not been reported. The results of this study reveal that it is possible to assess drought risk on crop yield using weather information before the growing season.

The risk-assessment accuracy improves with the growth stages as the crop develops. Although the accuracy rate for corn at preplanting is lower than that for soybeans, the rates improve quickly at later stages. At stage 2, when corn is at ovule development, the average correct assessment possibility reaches $85 \%$, indicating that a reliable assessment for corn begins at this point. For soybeans, a reliable assessment with $80 \%$ possibility begins at stage 3 , when soybeans are at pod formation stage. It needs to be noticed that the accuracy rate of stage 5 is $2 \%$ less than stage 4 . This indicates that weather in the last growth stage plays only a minor role in risk assessment, or may mislead the assessment, because soybeans that are near maturity do not respond to water stress as much as during the previous stages.

\subsubsection{Three typical situations among the risk-assessment results}

It was found that three typical situations exist among the classification results of the test dataset. The first situation is that risk on yield is assessed correctly from preplanting to the last stage during the years in which moisture supplies are consistently favorable or below normal. Second, risk is not assessed correctly at any of the stages during the years when short-term severe droughts or short-term sufficient moisture supply occur at critical growth stages and the long-term moisture supply is above normal or below normal. These short-term dry spells or sufficient rainfall at critical growth stages might have a negative or positive influence on the final yields. As a result, the crop would be damaged permanently or survive because of the short-term events. Third, risk is assessed correctly only at some of the stages when intermittent dry and wet spells occur. For instance, the SPI values show that water stress occurred at preplanting and stage 1, but water stress was over at later stages. Under this situation, the crop might recover from the damage during the remaining growth stages.

In addition, it was believed that water stress is not the only factor that affects crop yield because it is not absolute that the yield under favorable weather will be higher than that under poor weather. Therefore, some misclassified observations might be affected by factors other than drought, such as pests, hail, and so on. The observed yield data also have errors, which are difficult to quantify.

\subsection{Application of the risk-discriminant model in 2002}

Nebraska experienced a hot and dry growing season in 2002, with agricultural crop losses totaling $\$ 1.2$ billion (IANR, 2003). During the months of July, August, and September, the entire state was affected by drought conditions, with the majority of the state experiencing severe, extreme, or exceptional drought (NDMC, 2003). Nebraska Agricultural Statistics Service (NASS, 2002) indicated that, by the end of July, "dryland corn rated 5\% good and excellent, far below the average of 56\% and near 1974 levels." By 18 August, crop conditions changed little from the previous period, and subsoil moisture supplies were short or very short over $97 \%$ of the state. By the end of September, "dryland corn rated $5 \%$ good 
and excellent, far below the average of 47\%." Drought-related impacts include reduction of water levels in regional aquifers and dry wells in western Nebraska's Cheyenne County.

To provide a better visualization of agricultural drought risk-assessment, the riskassessment results were presented in a GIS. To create a state risk-assessment map, three data layers were required: a Nebraska map of county boundaries, a map of leading counties in crop harvesting, and a map of assessment results for each county with two classes: high and low risk. These data layers were processed and then combined to produce one coverage in ArcMap within ArcGIS 8.2.

The risk-assessment maps for corn from preplanting to stage 4 in 2002 are shown in figure 3. Counties shown in white have no, or minimal, rain-fed corn acres. The numbers appearing on the counties denote actual corn yield residuals for 2002. As defined previously, a county experiences a high agricultural drought risk if its yield residual is below -0.5 . Counties in light gray were identified by the model to have low risks on rain-fed corn yield at a specific growth stage, and counties in dark gray were identified as having high risks on dryland corn.
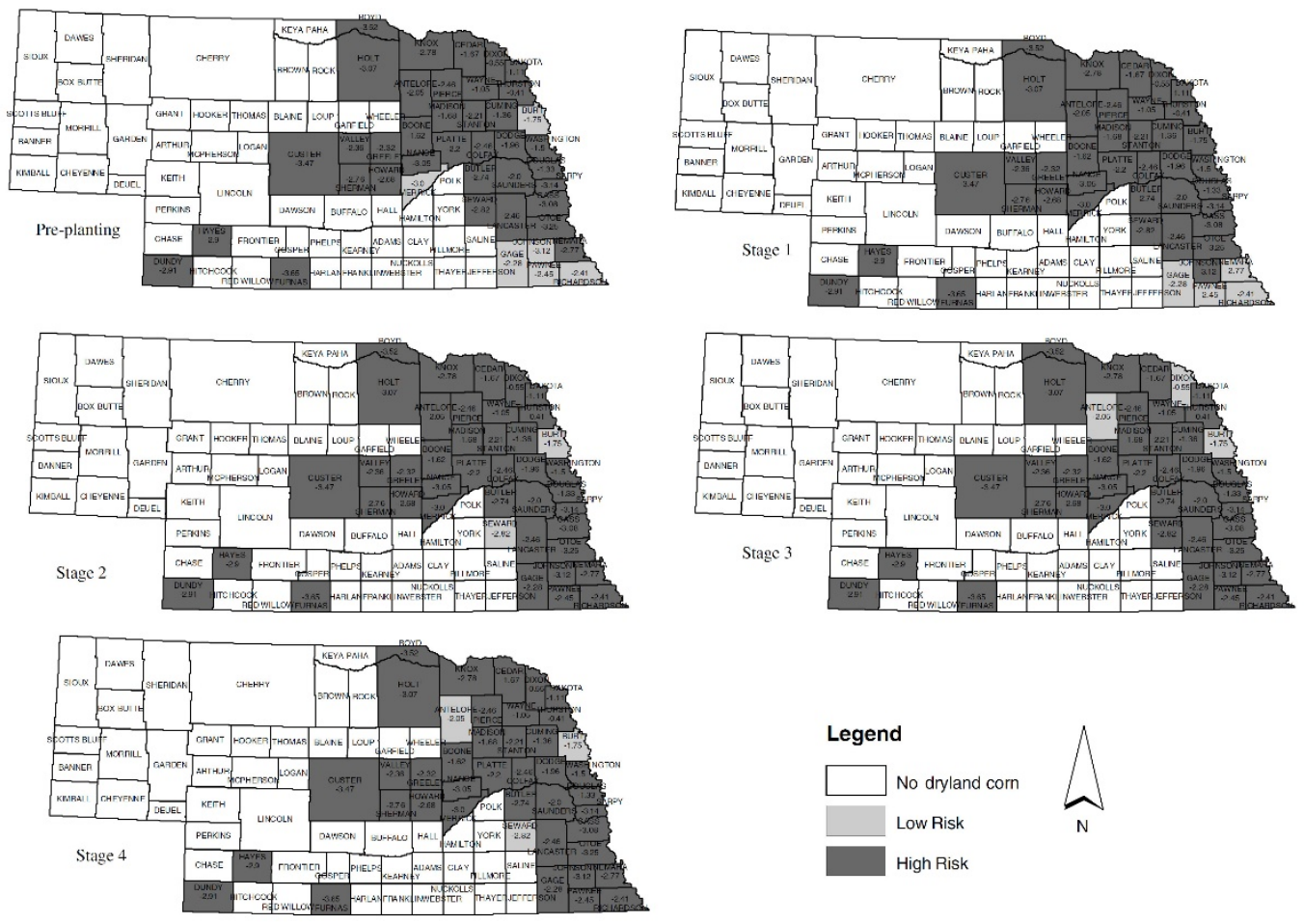

Figure 3. Agricultural drought risk assessment at preplanting through to stage 4 for 2002 nonirrigated corn. The numbers appearing on the counties denote actual 2002 corn yield residuals. Counties in white mean no or minimal nonirrigated corn acres were planted. Counties in light gray were classified into the low-risk group. Counties in dark gray were classified into the high-risk group. 
As indicated in figure 3, most of the leading counties in corn harvesting were classified into the high-risk group before the growing season, and only a few counties in the southeastern corner of the state show low risk for corn yield at preplanting and stage 1 (end of April and beginning of July). As the corn developed, the number of counties in the highrisk group increased, indicating that the majority of the leading counties in rain-fed corn planting were assessed as having high risks on corn yield in 2002. The final 2002 yields became available online by the end of May 2003, while this article was being prepared. All 2002 county corn yield residuals were below -0.5 except for Thurston County, which had a yield residual of -0.41 .

On the other hand, the risk assessment by the model for soybeans in 2002 indicated that soybeans were not as susceptible to drought as was corn. However, two-thirds of the leading counties in soybean planting in eastern Nebraska would have high agricultural drought risks.

\section{Conclusions}

The model described in this article can be used to assess real-time agricultural drought risk on specific crops at critical times before and during the growing season by retaining previous, and adding current, weather information as the crop passes through its various growth stages. Based on the research and results of the analyses, the following conclusions are drawn.

The integration of the SPI values at multiple time scales and the CSDI can describe features of moisture supply before and during the growing season that affect a crop's final yield.

The risk-assessment accuracy improves with the growth stages as the crop develops. In late July, when corn is at ovule development, assessment accuracy improves significantly. The average correct assessment possibility reaches $85 \%$, indicating that a reliable assessment for corn begins at this point. For soybeans, a reliable assessment with $80 \%$ possibility begins at mid-August, when soybeans are at pod formation stage. Generally, the final crop yields for the current year will be published officially in January or later in the next year. Thus, the model accomplishes the goal to assess drought risk on crop yield earlier.

Results show that both the high- and low-risk classification error rates for soybeans are higher than those of corn at most of the stages, indicating that weather has less lasting impacts on soybeans than on corn. Results also show that moisture supply from the last stage for both corn and soybeans plays only a minor role in risk assessment, or may even mislead the assessment. Therefore, the most accurate risk assessment can be made before crop harvesting.

The variables that dominate discriminant functions are similar between corn and soybeans. During the main growing season (from July to August) for corn and soybeans, the SPI values at the medium time scale (32 weeks) of the current stage contribute the most to the discrimination, followed by the 32-week SPI values of the previous stages.

It was also found that, during years in which moisture supplies are consistently favorable or below normal, the model is able to assess drought risk successfully at all critical times before and during the growing season. During years in which intermittent dry and 
wet spells occur, the model is able to assess drought risk successfully at some of the critical phenological times. During years in which short-term severe droughts or short-term sufficient moisture supply occur at critical growth periods, the crop would be damaged permanently or survive because of the short-term dry spells or sufficient rainfall. The model is not able to assess the crop risks under these circumstances. However, the model is designed to assess drought risk on the basis of historical and current weather information at each critical time period. Thus, the overall assessment ability is strong.

Acknowledgments - Support from the National Science Foundation Digital Government Program is gratefully acknowledged. We also thank the following individuals who made suggestions on this study: Mike Hayes, Albert Weiss, Mark Svoboda, Qi Hu, and Albert Peters. Finally, we would like to give thanks to Dr. Glenn McGregor and two anonymous reviewers for providing constructive comments for this manuscript.

\section{References}

Anon. 2002. The State of Nebraska Drought Mitigation and Response Plan. http://carc.nrc.state.ne.us/ carcunl/docs/planning.html [2004].

Bailey E, Boisvert RN. 1989. A comparison of risk efficiency criteria in evaluation groundnut performance in drought-prone areas. The Australian Journal of Agricultural Economics. 33(3): 153-169.

Belsley DA, Kuh E, Welsch RE. 1980. Regression Diagnostics: Identifying Influential Data and Sources of Collinearity. Wiley: New York.

Camargo MBP, Hubbard KG. 1999. Drought sensitivity indices for a sorghum crop. Journal of Production Agriculture 12(2): 312-316.

Chipanshi AC, Ripley EA, Lawford RG. 1997. Early prediction of spring wheat yields in Saskatchewan from current and historical weather data using the CERES-wheat model. Agricultural and Forest Meteorology 84: 223-232.

Da Mota FS. 1983. Weather-technology models for corn and soybean in the south of Brazil. Agricultural Meteorology 28: 49-64.

Dennett MD, Elston J, Diego QR. 1980. Weather and yields of tobacco, sugar beet, and wheat in Europe. Agricultural Meteorology 21: 249-263.

Dietz TJ, Put M, Subbiah S. 1998. Drought risk assessment for dryland agriculture in semi-arid Telangana, Andhra Pradesh, India. In: The Arid Frontier: Interactive Management of Environment and Development, Bruins HJ (ed). Kluwer Academic Publishers: Dordrecht, Netherlands; 143-161.

Dillon WR, Goldstein M. 1984. Multivariate Analysis: Methods and Applications. Wiley Series in Probability and Mathematical Statistics. Wiley: New York.

Draper NR, Smith H. 1998. Applied Regression Analysis, 3rd edition. Wiley: New York.

Duchon CE. 1986. Corn yield prediction using climatology. Journal of Climate and Applied Meteorology 25: 581-590.

Easterling WE, Isard SA, Warren P, Guinan P, Shafer M. 1988. Improving the detection of agricultural drought: a case Study of Illinois corn production. Agricultural and Forest Meteorology 43: 37-47.

Edwards DC, McKee TB. 1997. Characteristics of 20th century drought in the United States at multiple time scales. Atmospheric Science Paper No. 634, May; 1-30.

Flury B. 1997. A First Course in Multivariate Statistics. Springer-Verlag: New York. 
Wu, Hubbard, And Wilhite, International Journal of CLimatology 24 (2004)

Hill JD, Strommen ND, Sakamoto CM, Leduc SK. 1980. LACIE - an application of meteorology for United States and foreign wheat assessment. Journal of Applied Meteorology 19: 22-34.

HPRCC. 2003. High Plains Regional Climate Center. http://hprcc.unl.edu/ [2003].

IANR. 2003. Institute of Agriculture and Natural Resources, University of Nebraska-Lincoln. http:// ianrnews.unl.edu/static/0301162. shtml [2003].

Johnson RA, Wichern DW. 1998. Applied Multivariate Statistical Analysis, 4th edition. Prentice Hall: Upper Saddle River, NJ.

Keating BA, Meinke H. 1998. Assessing exceptional drought with a cropping systems simulator: a case study for grain production in northeast Australia. Agricultural Systems 57(3): 315-332.

Kumar V, Panu U. 1997. Predictive assessment of severity of agricultural droughts based on agroclimatic factors. Journal of the American Water Resources Association 33(6): 1255-1264.

Luo H, Skees JR, Marchant MA. 1994. Weather information and the potential for intertemporal adverse selection in crop insurance. Review of Agricultural Economics 16(3): 441-451.

Mahmood R, Hubbard KG. 2002. Effect of time of temperature observation and estimation of daily solar radiation for the Northern Great Plains, USA. Agronomy Journal 94(4): 723-733.

McDonald NS. 1989. Decision making using a drought severity index. Technical Memorandum Division of Water Resources, Institute of Natural Resources and Environment, CSIR, No. 89-5; 131139.

McKee TB, Doesken NJ, Kleist J. 1993. The relationship of drought frequency and duration to time scales. In Proceedings of the Eighth Conference on Applied Climatology. American Meteorological Society: Boston; 179-184.

Meyer SJ, Hubbard KG. 1995. Extending the crop-specific drought index to soybean. In 9th Conference on Applied Climatology. American Meteorological Society: 258-259.

Meyer SJ, Hubbard KG, Wilhite DA. 1991. The relationship of climatic indices and variables to corn (maize) yields: a principal components analysis. Agricultural and Forest Meteorology 55: 59-84.

Meyer SJ, Hubbard KG, Wilhite DA. 1993. A crop-specific drought index for corn: I. model development and validation. Agronomy Journal 86: 388-395.

NASS. 2002. Nebraska Agricultural Statistics Service. http://www.agr.state.ne.us/agstats/cropwthr .htm [2003].

NDMC. 2003. National Drought Mitigation Center. http://drought.unl.edu [2003].

NDMC/NOAA/USDA. 2003. NDMC/NOAA/USDA Drought Monitor. http://www.drought.unl .edu/dm/monitor.html [2003].

Nullet D, Giambelluca TW. 1988. Risk analysis of seasonal agricultural drought on low Pacific Islands. Agricultural and Forest Meteorology 42: 229-239.

Pochop LO, Cornia RL, Becker CF. 1975. Prediction of winter wheat yield from short-term weather factors. Agronomy Journal 67: 4-7.

Starr TB, Kostrow PI. 1978. The response of spring wheat yield to anomalous climate sequences in the United States. Journal of Applied Meteorology 17(8): 1101-1115.

Svoboda M, LeComte D, Hayes M, Heim R, Gleason K, Angel J, Rippey B, Tinker R, Palecki M, Stooksbury D, Miskus D, Stephens S. 2002. The drought monitor. The Bulletin of the American Meteorological Society 83(8): 1181-1190.

Taylor JK. 1990. Statistical Techniques for Data Analysis. Lewis Publishers. USDA. 2003. United States Department of Agriculture. http://www.usda.gov/nass/ [2003].

Walker GK. 1989. Model for operational forecasting of western Canada wheat yield. Agricultural and Forest Meteorology 44: 339-351. 
Wu, Hubbard, ANd Wilhite, International Journal of Climatology 24 (2004)

Wilhite DA. 1982. Measuring drought severity and assessing impact. In International Symposium on Hydrometeorology, Denver, CO, 13-15 June. American Water Resources Association: Bethesda, MD; 333-335.

Williams J, Murfield D (eds). 1977. Agricultural Atlas of Nebraska. University of Nebraska Press: Lincoln, NE.

Xu M. 1996. Wheat grain quality as related to climate: evaluation and model development. PhD dissertation, University of Nebraska-Lincoln. 